\title{
The Relation of Externalizing Behavior and Central Auditory Processing Deficits in 4-Year-Old Children
}

\author{
Cristina de Andrade Varanda1,2,3, Eva Cristina de Carvalho Souza Mendes ${ }^{1}$, \\ Nilva Nunes Campina1, Maria da Graça Giordano de Marcos Crescenti Aulicino1, \\ Rita de Cássia Gottardi van Opstal Nascimento ${ }^{3}$, Cláudia Maria Fernandes Marczak3, \\ Karla Regina de Jesus Grilo33, Elaine Cristina Diogo ${ }^{3}$, Fernanda Mello3, \\ Renata Cristina Borges Corrêa ${ }^{3}$, Fernanda Dreux Miranda Fernandes ${ }^{2}$ \\ ${ }^{1}$ Institute of Human Sciences, Paulista University, Santos, Brazil \\ ${ }^{2}$ Department of Physiotherapy, Speech-Language Pathology and Occupational Therapy, School of Medicine, \\ University of São Paulo, São Paulo, Brazil \\ ${ }^{3}$ Secretariat of Education, Santos City Hall, Santos, Brazil \\ Email: cristinavaranda@hotmail.com
}

Received 26 August 2015; accepted 6 October 2015; published 9 October 2015

Copyright (C) 2015 by authors and Scientific Research Publishing Inc.

This work is licensed under the Creative Commons Attribution International License (CC BY).

http://creativecommons.org/licenses/by/4.0/

(c) (i) Open Access

\section{Abstract}

The integrity of the central auditory system is a fundamental condition for language development. Good language development is related to good academic performance and adaptive behavior. Therefore, the evaluation of auditory processing along with behavior as well as the verification of a possible relationship between them can indicate possible ways on how to deal with both problem behavior and difficulties in language. 187 parents of preschoolers (mean age 3.8 years) were interviewed individually and asked to fill in the CBCL (Child Behavior Checklist), for ages 1(1/2) to 5 , providing a behavioral profile concerning externalizing and internalizing behavior. Children were assessed regarding central auditory processing skills through the Simplified Assessment of the Auditory Processing-SAAP (Pereira \& Schochat, 1997) including Sound Source Localization (SSL); Non-Verbal Sound Sequence Memory (NVSSM); Verbal Sounds Sequence Memory (VSSM). To investigate a possible association between central auditory processing skills and behavioral problems, all the scores in CBCL and the total scores of Simplified Auditory Processing Assessment were correlated with functional parameters using the Spearman rank correlation. The behaviors "acts too young for age"; "constantly seeks help"; "does not eat well”; "does not seem to feel guilty after misbehaving"; "easily frustrated"; "nervous movements or twitching"; "nervous, highstrung, or tense"; "poorly coordinated or clumsy"; "repeatedly rocks head or body"; "stares into space and seems preoccupied", "sulks a lot" and "wanders away" were correlated with poor auditory pro- 
cessing skills. This indicates that the school staff along with health professionals should provide informational counseling regarding, not only the communicative difficulties associated with a poor performance on central auditory processing skills but also the psychosocial difficulties that these children may be facing.

\section{Keywords}

\section{Language Development, Child Behavior, Evaluation}

\section{Introduction}

The way the brain processes the sounds which are received from the environment refers to its ability to analyze their distinguishing physical characteristics such as frequency, intensity, and temporal features. Then the brain constructs an "image" of the signal from these component parts for comparison with stored "images." If a match occurs, it is possible to understand what is being said and to recognize sounds that have important meanings (sirens, doorbells, crying, etc.) (Schminky \& Baron, 2000). Central auditory processes are the mechanisms and processes of the auditory system responsible for some behavioral phenomena such as sound localization and lateralization; auditory discrimination and pattern recognition; temporal aspects of hearing; auditory performance decrements with competing acoustic signals and auditory performance decrements with degraded acoustic signals (ASHA, 1996).

The integrity of the central auditory system is a fundamental condition for language development. Successful language development is related to good learning abilities and academic success (Bishop \& Adams, 1990; Capovilla \& Dias, 2008; Sharma, Purdy, \& Kelly, 2009). Individuals with auditory processing deficits tend to present behavioral manifestations occurring in isolated or associated forms, including verbal communication and writing, academic performance, social behavior and hearing (Jorge, 2006). Besides, there seems to be a high frequency of symptoms related to academic and behavioral difficulties in patients with auditory processing disorders (Fridlin, Pereira, \& Perez, 2014).

Besides the effect language has on learning, it affects behavior as well. Language is important for regulating attention and behavior. Language and communication skills can also interfere with socialization (Petersen et al., 2013). When children can communicate their needs they can use more reasoning in negotiating with adults and their peers, preventing them to develop problem behavior. Concerning social behavior, research has shown that externalizing behavior problems in preschoolers can have a negative impact on their development (Homem, 2013). Childhood behaviors marked by defiance, impulsivity, disruptiveness, aggression, antisocial features, and overactivity are called undercontrolled, or externalizing (Hinshaw, 1992). These problems are also related to academic underachievement.

Therefore, both the evaluation of the auditory processing skills and the behavioral assessment can be helpful for the early identification of children at risk for learning disabilities and also to indicate behavioral problems that can be associated with central auditory impairment.

The purpose of this study was to compare behavioral profiles with central auditory processing deficits in preschoolers. The hypothesis is that children who present deficits in auditory processing skills present behavioral difficulties which shall indicate an association between those deficits and some externalizing behaviors. This finding could facilitate a broader understanding on how to handle some behavioral issues among children who have central auditory processing deficits.

\section{Methods and Material}

The research project's participants were 187 parents of preschoolers (mean age 3.8 years). They were participants of a larger research which aimed to investigate the effects of an intervention to develop language abilities and behavioral skills among preschoolers. They were recruited from four different schools whose principals agreed to take part in the research study. Using the occupational scale proposed by Hollingshead (2011), almost half of parents fall into the 3rd and 4th categories (machine operators, semiskilled workers, smaller business owners, skilled manual workers, craftsmen); $11 \%$ are classified as menial service workers; $8 \%$ as unskilled 
workers; another $8 \%$ did not inform their occupation; only 5\% are classified as technicians, semiprofessionals, small business owners, another $5 \%$ are classified as administrators and proprietors of medium-sized businesses; $4 \%$ of them are sales workers; another $4 \%$ are unemployed; $3 \%$ of them are managers and minor professionals and only $2 \%$ of them are higher executives, proprietors or large businesses and major professionals. These parents were interviewed individually and asked to fill in the CBCL (Child Behavior Checklist) (Achenbach \& Rescorla, 2000; Bordin et al., 1995), for ages 1(1/2) to 5 years, which provides a behavioral profile concerning externalizing and internalizing behavior. High scores in CBCL indicate behavioral problems once parents are asked to quantify the behavioral problem presented by their children in the past two months using a scale of 0-1-2 points that indicates respectively: false item or absent behavior (0); partially true item or sometimes present behavior (1); and really true item or frequently present (2). There are 100 statements presenting possible behavioral problems. Different behaviors are related to different domains: emotionally/reactive; anxious/depressed; somatic complaints; withdrawn; attention problems and aggressive behavior.

Children were assessed regarding central auditory processing skills through the Simplified Assessment of the Auditory Processing — SAAP (Pereira \& Schochat, 1997) including Sound Source Localization (SSL); NonVerbal Sound Sequence Memory (NVSSM); Verbal Sounds Sequence Memory (VSSM). Bells, agogos (percussion metal musical instruments), coconut shells and rattles were used in the simplified auditory processing evaluation. The Sound Source Localization (SSL) assesses the ability to locate the sound source come from five different directions. Individuals are instructed to point to the direction of where they think the sound comes from. This test may be carried out with a rattle. The Non-Verbal Sound Sequence Memory (NVSSM) assesses the ability of sequential memory for nonverbal sounds. First the sounds of each instrument are separately presented for the subject to acknowledge each instrument. Next, four sequences of sounds with variations in the order of instruments are played and the subject must turn and point to and/or name the sequence heard, without seeing the sequence played. The Verbal Sounds Sequence Memory (VSSM) assesses the ability of the subject to repeat the syllables $/ \mathrm{pa} /, / \mathrm{ta} /$ and $/ \mathrm{ka} /$ presented in three different orders.

To investigate a possible association between central auditory processing skills and behavioral problems, all the scores in CBCL and the total scores of Simplified Auditory Processing Assessment were correlated with functional parameters using the Spearman rank correlation. The adopted level of significance was $5 \%(p \leq 0.05)$. The research was proceeded with the consent of the Ethics Committee for the Analysis of Research Projects of the School of Medicine-Universidade de São Paulo (USP) under number 381/14. The adults responsible for the children signed the consent form.

\section{Results and Discussion}

Some specific behaviors identified through the answers obtained in CBCL were negatively correlated, with statistical significance, with central auditory processing skills through the total punctuations obtained in SAAP, indicating that poor performance in central auditory processing was correlated with the stronger presence of behavioral problems. Table 1 presents the significant negative correlation obtained between behavior and central auditory skills.

Unexpectedly, two behaviors were positively correlated with central auditory processing skills: aches or pains without medical cause and diarrhea or loose bowels when not sick.

There were two types of behavior found in "emotionally reactive", "aggressive behavior" and in "attention problems" domains. There was one type of behavior found in the "withdrawn" and one in the "attention problems" domain. The other behaviors were classified as "other problems". It is expected that difficulties in processing sounds adequately can interfere in the ability of the individual to relate with the environment and others. Attention problems can be the result of failures in following instructions or speech successfully. It is hard for someone to focus his attention on information he cannot fully comprehend. Or attention problems can co-occur with language deficits (Petersen et al., 2013). Petersen et al. (2013) state that one possible mechanism linking language to attention and behavior problems would be the use of language in the form of private (self-directed) speech as a regulator. This would improve behavioral regulation. Again this self-directed speech is dependent on how well the children are able to process the acoustic information come from the environment. Likewise, withdrawn responses could be a way of escaping the aversive or not fully understood situation. Aggressive and emotionally reactive responses could also be a way of dealing with inaccurately processed environmental information. In this case, when not understanding what happens in the environment, one can become anxiety prone which leads to emotionally reactive responses and aggressive behavior. 
Table 1. Spearman significant correlations between CBCL behavioral item scores and Simplified Auditory Assessment Processing (SAAP) scores.

\begin{tabular}{lc}
\hline \multicolumn{1}{c}{ Behavior } & Spearman correlation \\
\hline Acts too young for age & $\mathrm{r}=187$ \\
& $\rho=0.195$ \\
Constantly seeks help & $\mathrm{r}=-0.152$ \\
& $\rho=0.038$ \\
Does not eat well & $\mathrm{r}=-0.154$ \\
& $\rho=0.036$ \\
Does not seem to feel guilty after misbehaving & $\mathrm{r}=-0.163$ \\
& $\rho=0.026$ \\
Easily frustrated & $\mathrm{r}=-0.171$ \\
Nervous movements or twitching & $\rho=0.019$ \\
Nervous, highstrung, or tense & $\mathrm{r}=-0.167$ \\
& $\rho=0.022$ \\
Poorly coordinated or clumsy & $\mathrm{r}=-0.174$ \\
Repeatedly rocks head or body & $\rho=0.017$ \\
& $\mathrm{r}=-0.169$ \\
& $\rho=0.021$ \\
& $\mathrm{r}=-0.177$ \\
& $\rho=0.016$ \\
& $\mathrm{r}=-0.169$ \\
& $\rho=0.021$ \\
& $\mathrm{r}=-0.183$ \\
& $\rho=0.012$ \\
& $\mathrm{r}=-0.183$ \\
& $\rho=0.012$ \\
\hline
\end{tabular}

\section{Conclusion}

The findings of this investigation indicate that children with poor central auditory processing skills experience significant emotional and social difficulties. The school staff along with health professionals should provide informational counseling regarding, not only the communicative difficulties associated with a poor performance on central auditory processing skills but also the psychosocial difficulties that these children may be facing.

\section{Acknowledgements}

The authors thank FAPESP_-Research Support Foundation of the State of São Paulo and Maria Cecília Souto Vidigal Foundation for funding.

\section{References}

Achenbach, T. M., \& Rescorla, L. (2000). Manual for the ASEBA Preschool Forms \& Profiles. Burlington: University of Vermont, Research Center for Children, Youth, and Families.

ASHA-American Speech-Language-Hearing Association (1996). Task Force on Central Auditory Processing Consensus Development: Central Auditory Current Status of Research and Implications for Clinical Practice. Journal of the American Academy of Audiology, 5, 41-54.

Bishop, D. V. M., \& Adams, C. (1990). A Prospective Study of the Relationship between Specific Language Impairment, Phonological Disorders and Reading Retardation. Journal of Child Psychology and Psychiatry, 31, 1027-1050. http://dx.doi.org/10.1111/j.1469-7610.1990.tb00844.x

Bordin, I. A. S., Mari, J. J., \& Caeiro, M. F. (1995). Validação da versão brasileira do “Child Behavior Checklist” (CBCL) 
(Inventário de Comportamentos da Infância e adolescência): Dados preliminares. Revista ABP-APAL, 17, 55-66.

Capovilla, A. G. S., \& Dias, N. M. (2008). Habilidades de linguagem oral e sua contribuição para a posterior aquisição de leitura. Psic: Revista da Vetor Editora, 9, 135-144.

http://pepsic.bvsalud.org/scielo.php?script=sci_arttext\&pid=S1676-73142008000200002\&lng=pt\&tlng=pt

Fridlin, S. L., Pereira, L. D., \& Perez, A. P. (2014). Relação entre dados coletados na anamnese e distúrbio do processamento auditivo. Revista CEFAC, 16, 405-412.

http://www.scielo.br/scielo.php?script=sci_arttext\&pid=S1516-18462014000200405\&lng=en\&tlng=pt.10.1590/1982-021 $\underline{6201416312}$

http://dx.doi.org/10.1590/1982-0216201416312

Hinshaw, S. P. (1992). Externalizing Behavior Problems and Academic Underachievement in Childhood and Adolescence: Causal Relationships and Underlying Mechanisms. Psychological Bulletin, 3, 127-155. http://dx.doi.org/10.1037/0033-2909.111.1.127

Hollingshead, A. B. (2011). Four Factor Index of Social Status. Yale Journal of Sociology, 8, 21-51.

Homem, T. C., Gaspar, M. F., Santos, M. J. S., Azevedo, A. F., \& Canavarro, M. C. (2013). Perturbações de comportamento externalizante em idade pré-escolar: O caso específico da perturbação de oposição. Análise Psicológica, 31, 31-48. http://www.scielo.mec.pt/scielo.php?script=sci arttext\&pid=S0870-82312013000100003\&lng=pt\&tlng=pt http://dx.doi.org/10.14417/ap.658

Jorge, T. C. (2006). Avaliação do processamento auditivo na educação infantil. Master’s Thesis, Campinas, São Paulo: Pontifícia Universidade Católica de Campinas.

Pereira, L. D., \& Schochat, E. (1997). Processamento Auditivo Central: Manual de avaliação. São Paulo: Lovise.

Petersen, I. T., Bates, J. E., D’Onofrio, B. M., Coyne, J. E. L., Dodge, K. A., Pettit, G. S., \& Van Hulle, C. A. (2013). Language Ability Predicts the Development of Behavior Problems in Children. Journal of Abnormal Psychology, 122, 542557. http://dx.doi.org/10.1037/a0031963

Schminky, M. M., \& Baron, J. A. (2000). Central Auditory Processing Disorders: An Overview of Assessment and Management Practices. http://www.tsbvi.edu/Outreach/seehear/spring00/centralauditory.htm

Sharma, M., Purdy, S. C., \& Kelly, A. S. (2009). Comorbidity of Auditory Processing, Language and Reading Disorders. Journal of Speech, Language, and Hearing Research, 52, 706-722. http://dx.doi.org/10.1044/1092-4388(2008/07-0226) 